\title{
The Pyramid Club Elementary School-Based Intervention: Testing the Circle Time Technique to Elicit Children's Service Satisfaction
}

\author{
Madeleine Ohl ${ }^{1}$, Pauline Fox ${ }^{2} \&$ Kathryn Mitchell ${ }^{3}$ \\ ${ }^{1}$ Office of the Dean of Students, University of West London, St Mary's Road, London, W5 5RF, UK \\ ${ }^{2}$ School of Psychology, Social Work and Human Sciences, University of West London, Paragon, Boston Manor \\ Road, Brentford, TW8 9GA, UK \\ ${ }^{3}$ Directorate, University of West London, St Mary's Road, London, W5 5RF, UK \\ Correspondence: Madeleine Ohl, Office of the Dean of Students, University of West London, St Mary's Road, \\ London, W5 5RF, UK. Tel: 44-0208-231-2079. E-mail: Maddie.ohl@uwl.ac.uk
}

Received: September 13, 2013

doi:10.5539/jedp.v3n2p204

\author{
Accepted: October 8, $2013 \quad$ Online Published: October 18, 2013 \\ URL: http://dx.doi.org/10.5539/jedp.v3n2p204
}

\begin{abstract}
Children's views of the social-emotional health services they use are important to service evaluation and development. However, often it is parental or clinician feedback that is gathered. In the current study Circle Time groups were run to identify children's satisfaction with the Pyramid Club School-based intervention and to test the salience of this technique in eliciting children's views. Children evaluated Clubs positively, reported no adverse effects and suggested ways to develop the intervention. The efficacy of Pyramid Clubs in building social-emotional competencies is supported by the children's qualitative reports and Circle Time proved a salient technique for eliciting the views of young children.
\end{abstract}

Keywords: children's perspective, circle time, participation, social-emotional health

\section{Introduction}

The majority of children's service satisfaction studies are based on parental feedback rather than responses of the service users themselves i.e., the children (Stallard, 1995, 2001). Hennessy's (1999) review of methods to establish children's satisfaction with child and adolescent health services in the United Kingdom (UK) reported that very few measures relate directly to the children themselves with most items being generated by parents or clinicians. This may be due to the perception that there exists a critical age at which children can independently express their viewpoint reliably. This might also explain why many validated and widely used pencil and paper measures do not have self-report versions for children before the age of 11 (e.g., the Strengths and Difficulties Questionnaire (SDQ), Goodman, 1997). Given the discrepancies that can exist between accounts of mental health difficulties and therapies between child, parent and professional, it is essential that the unique contribution of the child or young person is actively sought using methods that are salient to them (DiBartolo \& Grills, 2006). Moreover, this participatory approach may be critical for the growth of identity and have a beneficial impact on children's social-emotional health (Graham \& Fitzgerald, 2011). Therefore, there remains a need for a better understanding of how children experience school-based and other child related services so their views can inform future intervention development, delivery and evaluation.

The importance of services users' participation has gained added prominence in terms of both policy making and practice both in the UK and internationally (Department of Health, 2004; Day, 2008). This is principally due to policy that promotes the Children's Rights agenda and to research showing that, rather than being passive beneficiaries of interventions, children can be active stakeholders in the process (Alderson, 2010, Worrall-Davies, 2008).

Despite this consensus on the importance of eliciting children's views, the most effective method of accessing young children's views is unclear. One barrier to ensuring that methods used are salient to the child stakeholders may be that as Alderson points out 'Adults are primarily accountable to systems that manage, evaluate and fund the services not to the children' (Alderson, 2010, p91). In addition a systematic review (Worrall-Davies \& Marino-Francis, 2008) of six methodological approaches (quantitative and qualitative) found no clear evidence of the most effective method. However, none of the reviewed studies used Circle Time - a school and Child and 
Adolescent Mental Health Service activity widely used throughout the UK. Yet there are clear advantages for using Circle Time as children see it as an intrinsic part of the intervention and may feel more confident in putting forward true and diverse views. Furthermore, Sim (1998) observed that children tend to be more relaxed amongst their peers and, therefore, more likely to express and explore their opinions than when interviewed alone with an adult.

Circle Time is an integral part of the Pyramid after-school intervention (see Ohl, Mitchell, Cassidy \& Fox, 2008 for Pyramid details). However, Pyramid evaluation research (Ohl et al., 2008, Ohl, Fox \& Mitchell, 2012; McKenna, Cassidy \& Giles, 2013) has focused on intervention efficacy using quantitative teacher observer-ratings of children rather than on the views of the children themselves. Therefore, the aims of the current research were to examine qualitatively the children's views of the quality and efficacy of the Pyramid intervention, and to investigate the use of Circle Time as a technique to elicit these views.

\section{Method}

\subsection{Participants}

Participants were 27 children (15 girls and 12 boys) who had all been selected for and had attended a Pyramid Club in the Autumn (Fall) term of the same academic year. All eligible children took part in Circle Time groups run in the following summer term. Fourteen of the children were pupils from two Primary (elementary) schools in West London and thirteen were from an East London school in the UK. All schools were situated in areas where there was a higher than average uptake of free school meals (FSM). The mean free school meals take up was $38 \%$ with a range of $55.8 \%-24.3 \%$. This is an indicator of low household income within the catchment area and double the current UK national average (17\%) (Department for Education, 2013).

In keeping with the diversity of the areas of London where the schools were situated, the study sample included children of Asian Indian ( $n=7)$, Asian Pakistani $(n=2)$, Black African $(n=4)$, Black Caribbean $(n=6)$, Mixed White/Caribbean $(n=4)$, White British $(n=2)$ and White Eastern European $(n=3)$ origin. At the time the Circle Time groups took place, all the children were aged between 8 and 9 years old (mean age 8.74 years). Parental permission was obtained using opt-out consent whereby parents were expected to return the form only if they did not want their child to participate (see Day, Carey \& Surgenor, 2006; Field, Lawson \& Banerjee, 2008). No parents opted to withdraw their child from the study. Children did not give written consent to take part in the intervention or the Circle Time evaluation; however, they were invited to attend the Pyramid clubs of which Circle Time is an integral time. The high level of attendance showed children's willingness to attend. Ethical approval was granted by a University ethics committee in line with British Psychological Society ethical guidelines.

\subsection{Design and Procedure}

Three Circle Time groups were held. Each one took place in the same room that had been used for the Pyramid Club the children had attended. The rooms were laid out as for a Circle Time session with chairs arranged in a circle and an audiotape recorder was placed in the centre.

\subsection{Pyramid Club Intervention and Intervention Dosage}

Pyramid clubs for children offer a therapeutic group-work early intervention for children aged 7-14. Normally run as a targeted after-school club in order to minimise stigma and make it accessible to the widest number of children, the clubs run for 10 weeks for 1.5 hours a week, offering a developmental programme for those children who internalise their difficulties and are showing early signs of mental health problems such as social withdrawal, somatic disorders, depression and anxiety. Children are selected for Pyramid clubs using the Goodman's Strengths and Difficulties Questionnaire (SDQ) (Goodman, 1999), with a focus on those children with abnormal or borderline scores in the peer, emotional or pro-social categories (Pyramid, 2011). Intervention dosage, participation rates and attrition are three of the five integral components identified by Mihalic and colleagues through which the implementation fidelity of a programme can be monitored, (Mihalic, Irwin, Elliott, Fagan \& Hansen, 2001). Therefore, the participation rate of attendees can be considered an important factor in the evaluation of a programme not only as this implies that participants with irregular attendance are receiving less intervention 'dosage' but also that low participation rates may pose an attrition threat to the study (Mrazek \& Brown, 2002). To prevent the occurrence of such a threat to the integrity of the current evaluation, an optimum participation rate for all children assigned as attendees to the Pyramid intervention group has been identified. This rate was set at $70 \%$ attendance (i.e., seven out of the 10 sessions) as it was reasoned that this represents the minimum number of sessions needed to ensure that the children have formed a cohesive and functional group from which they might benefit from having membership (Pyramid, 2011). All the children who 
took part in the current study had completed seven or more of the Pyramid sessions to which they had been selected to attend.

\subsection{Facilitators}

Four facilitators took part in the Circle Time groups (two per group). All had lengthy experience of working with children; two also had extensive experience of running children's Circle Time. None of the facilitators were previously known to the children in their group. All facilitators were briefed by the lead researcher beforehand who emphasised that it was their responsibility to manage the behaviour of the group to ensure that whilst all children were encouraged to take part fully they should also be protected from over-disclosure.

\subsection{Circle Time Questions}

To engage children in suggesting how the Club could be developed and to reduce socially desirable responses, the children were not specifically asked for negative comments about their Club. Instead, to explore how the children felt the Club could be developed questions were phrased in a positive manner. This technique is becoming increasingly widespread. For example, in a review of the UK Child and Adolescent Mental Health Service (CAMHS), children were asked to identify three factors that made them feel good about themselves and were important to their emotional health and well-being (DCSF, 2008). This approach encourages service users to identify their needs whilst focusing on positive factors that enhance self-concept rather than negative factors linked to socio-emotional difficulties. In addition, children were asked how they would improve Pyramid after they had had an opportunity to explain what they liked about their Club. In this way it was hoped to build the children's confidence to offer constructive and creative suggestions. The Circle Time questions are shown in Table 1.

Table 1. Focus group questions

\begin{tabular}{l}
\hline Focus Group Questions: Year 3 Pyramid Attendees \\
\hline Q.1. Tell me a bit about what you did at Pyramid Club... \\
Q.2. What was the best thing about Pyramid? \\
Q.3. Why was this important to you? \\
Q.4. Has coming to Pyramid Club helped you and if so how? \\
Q.5. Has taking part changed how you feel about things? For example; school, your schoolwork, \\
friends... \\
Q.6. What changes have your family/friends/school noticed in you? \\
Q.7. If you had a magic wand and you could change something about Pyramid Club what would you \\
change?
\end{tabular}

\subsection{Circle Time Protocol}

Each Circle Time group had two facilitators; the lead facilitator asked questions and the other made field notes. The children were greeted and invited into the room by one facilitator whilst the other was sitting waiting in the circle. An ice-breaker game was played to put the children at their ease (Day et al., 2006; Fox et al., 2006). The lead facilitator then invited everyone to sit and explained some 'ground rules' for the group. The facilitators introduced themselves and each explained their role. The children were then encouraged to introduce themselves to one another within the group. Through these Circle Time techniques, the facilitators aimed to 'deprivilige' their adult status and avoid leading the children in their responses. Thus the facilitator role was principally to 'scaffold' the conversation process between the children of their shared experience (Graham \& Fitzgerald, 2011). Children were given labels with a number to wear and asked to refer to each other by their numbers whilst the audiotape was recording and told that it was not necessary to reveal personal details (Day et al., 2006). The audiotape recorder was then switched on and the lead facilitator began the Circle Time questions. All children were given the opportunity to answer each question posed and this was facilitated by the use of a circle time object (a soft toy) passed around the group with whoever had the toy holding the floor. Children were not forced to respond and could pass the toy on when it was their turn. However, at the end of each question children who had 'passed' when it was their turn were offered another opportunity to speak. This ensured everyone's views 
were heard including those of any children who were less comfortable speaking within a group. Therefore the skills of the facilitator were paramount in the management of each group's dynamic.

Circle Time sessions lasted no more than forty minutes (the length of an average elementary school lesson) as this was considered to be the optimum time span to keep participants' attention considering their age. Once the children had finished speaking, the tape was switched off. The children were thanked for their participation and encouraged to ask any questions about the purpose of the Circle Time.

\subsection{Data Analysis}

The audiotapes were transcribed verbatim and analysed using thematic analysis (Boyatzis, 1998; Braun \& Clarke, 2006; Bryman, 2012). Thematic analysis has been described as a 'foundational method for qualitative analysis' (Braun \& Clarke, 2006, p78) and shares generic skills such as thematic coding with more epistemological qualitative approaches such as grounded theory (Strauss \& Corbin, 1998) and Interpretative Phenomenological Analysis (IPA) (Smith, 2004). It is used to generate and explore 'themes' within a data set and can employ either a data driven 'bottom-up' approach (e.g., grounded theory, Strauss \& Corbin, 1998) or can be used to address pre-determined questions about the data in a more 'top-down' approach (Boyatzis, 1998). However, as thematic analysis is not driven by one particular theory, it offers flexibility whilst still providing a research tool that can produce a rich and detailed analysis suited to the complexity of personal experiential data (Braun \& Clarke, 2006, Fox et al., 2006).

The three transcripts were read completely several times by the lead researcher and a co-researcher who both had prior experience of researching Pyramid using thematic analysis (Fox, et al. , 2006). The children's responses (phrases and sentences) were used as units of coding. These responses were then analysed for their manifest and latent content and, as a result, four over-arching coding categories (themes) were derived from the data.

\subsection{Themes}

1) Meeting the Pyramid intervention ethos: Pyramid attendees identify experiencing activities at the Clubs that reflect the four elements of the Pyramid intervention ethos, namely; Love \& Security, Praise \& Recognition, New Experiences and Responsibility.

2) Self-reported changes and benefits: Pyramid attendees explain the benefits they have derived from the Club e.g., feeling more confident, participating in class more, feeling less nervous or shy and making new friends.

3) Changes and benefits noticed by others: Pyramid attendees mention that others have remarked on changes in their behaviour at home or at school e.g., they are chattier, more confident or more settled, their teacher has noticed improvements in their schoolwork.

4) Suggested Club changes: Pyramid attendees' suggestions for changing or improving the Pyramid Club format.

The three transcripts were subjected to an iterative process to determine inter-coder reliability using a method described by Hrushka, Schwartz, Cobb-St John, Picone-Decaro, Jenkins \& Carey (2004). A random sample of three sheets was taken from each transcript and independently coded by both coders using the coding categories listed above. Once these sheets were fully coded they were compared for items of agreement and inter-coder reliability was tested using Cohen's Kappa (Cohen, 1960). Cohen's Kappa was selected as it adjusts for agreement by chance (Cohen, 1960, Hrushka et al., 2004) rather than other coefficients of agreement that compare the proportion of actual inter-coder agreement only. At the second coding round, the inter-coder sampling of the current dataset generated a Kappa statistic of 0.69 , which is described as 'substantial' (Landis \& Koch,1977) or 'good' (Bryman, 2012). This level of inter-coder reliability was considered acceptable and the lead researcher coded the entire dataset using the four themes previously identified. Table 2 shows the coding framework. 
Table 2. Table of themes for Pyramid focus group data

\begin{tabular}{|c|c|c|}
\hline Theme & Description & Examples \\
\hline $\begin{array}{l}\text { Meeting the Pyramid } \\
\text { intervention Ethos }\end{array}$ & $\begin{array}{l}\text { Attendees report taking part in } \\
\text { activities that reflect the four } \\
\text { part Pyramid ethos: Love \& } \\
\text { Security, Praise \& Recognition, } \\
\text { Responsibility and New } \\
\text { Experiences }\end{array}$ & $\begin{array}{l}\text { We made a party and brought food and sweets } \\
\text { and um things } \\
\text { Transcript } 3 \text { : line } 6 \\
\text { I enjoyed when we was making the bread... } \\
\text { Transcript } 3 \text { : line } 47 \\
\text { Well we had rules - so that is important...not } \\
\text { to fight } \\
\text { Transcript } 3 \text { : line } 55\end{array}$ \\
\hline $\begin{array}{l}\text { Attendee self-reported } \\
\text { changes and benefits }\end{array}$ & $\begin{array}{l}\text { Attendees report any changes or } \\
\text { benefits they recognise in } \\
\text { themselves that they attribute to } \\
\text { attending. }\end{array}$ & $\begin{array}{l}\text { I think I feel more confident um when I had } \\
\text { worries before um it has made me feel better. } \\
\text { Transcript 2: lines 59-60 } \\
\text { Feeling less nervous } \\
\text { Transcript 2: line } 63\end{array}$ \\
\hline $\begin{array}{l}\text { Changes and benefits } \\
\text { noticed by others }\end{array}$ & $\begin{array}{l}\text { Attendees report that others } \\
\text { (e.g., parents/teachers) have } \\
\text { commented on changes in how } \\
\text { they are in themselves } \\
\text { post-Club. }\end{array}$ & $\begin{array}{l}\text {...my Mum said that I am talking...chatty.. } \\
\text { Transcript 2: line } 76 \\
\text { Um my Mum is glad I joined the club as it has } \\
\text { taught me lots of new stuff... } \\
\text { Transcript 3: line } 87\end{array}$ \\
\hline $\begin{array}{l}\text { Costs noticed by self and or } \\
\text { others }\end{array}$ & $\begin{array}{l}\text { Any costs identified by either } \\
\text { attendees or others attributed to } \\
\text { attending. }\end{array}$ & None reported \\
\hline Suggested changes & $\begin{array}{l}\text { Attendees' ideas for improving } \\
\text { Pyramid Clubs. }\end{array}$ & $\begin{array}{l}\text { I think if it was for whole classes it would } \\
\text { even it out, more could come } \\
\text { Transcript 1: lines 140-141 } \\
\text { To have more time } \\
\text { Transcript 2: line } 90\end{array}$ \\
\hline
\end{tabular}

\section{Results}

Four over-arching themes were identified from coding the three focus group transcripts. These themes related to the Pyramid attendees' experience of taking part in a Pyramid Club and are outlined and illustrated by verbatim extracts.

\subsection{Meeting the Pyramid Intervention Ethos}

The Pyramid intervention ethos is based upon four key principles namely 'Love and Security', 'Praise and Recognition', 'New Experiences' and 'Responsibility'. Therefore this first thematic category encompassed all comments related to the children's experience of Club activities that relate to these four elements.

Ethos 1: Love and Security

Many of the activities the children liked best can be interpreted as 'nurturing'. For example, many involved cooking and eating food, playing games, and having fun:

C27: Well um, well I enjoyed when we was making bread. (Transcript 3, line 47)

C25: Um...we...we...we played games and we had a little snack, the snack was my favourite part of the club....I liked the food best. (Transcript 3, lines 17-19)

The need for feeling secure was also mentioned:

C26: Well we had rules - so that's important ...to not fight...to be safe (Transcript 3, lines 55-57) 


\section{Ethos 2: Praise and Recognition}

The children equated praise and recognition with being reinforced with a reward token, such as a prize or sticker as they might be for producing good work in class. Nonetheless, this illustrates how the children recognise a need for achieving targets and goals:

C12: ... you can get a gold medal and certificates (Transcript 1, line 25)

C4: [Cuts in] and stickers (Transcript 1, line 26)

Ethos 3: New Experiences

For many children the best part of attending Pyramid was the opportunity to try new things including art and craft activities, theatre trips and new games:

C2: We had pizza and ice cream and a bag with some stuff in it...

C5: We went bowling (Transcript 1, lines 52 and 54)

C20: Colouring and making t-shirts and having fun with the leaders and discussing things (Transcript 2, lines 27-28)

\section{Ethos 4: Responsibility}

The children acknowledged that their allocation of a Pyramid Club place might be unfair on others in their class who had not received a place. They also recognised the importance of working as a team:

C25: ...I wish there was more but I feel we have to give other children the chance (Transcript 3, lines 126-127)

C18: I think if it (Pyramid Club) was for a whole class it would even it out; more could come (Transcript 1, lines 140-141)

C18: Because it got us working as a team (Transcript 2, line 38)

\subsection{Self-Reported Changes and Benefits}

The second theme addressed changes that attendees perceived in themselves after participating in a Pyramid Club. The responses varied between children who were more insightful about their feelings and how they had changed and those who were more pragmatic and related progress made to school-related improvement such as increased participation in class:

C25: Um...I feel confident as well because we have been doing so much talking at first I never use to put my hand up (in class) now I am (Transcript 3, lines 65-66)

Several children reported that coming to the Club had helped them with shyness and made them less fearful:

C2: When the Club started I was a bit shy but now I am not shy I like it because I am not scared anymore (Transcript 1, lines 145-146)

C26: I was shy too ...um my Mum said that I am talking...chatty (Transcript 3, lines 70, 72 and 76)

Many children reported benefits gained from forming relationships with the volunteer Club Leaders. Leaders were perceived as being approachable, understanding and helping children to cope with their feelings. Additionally, some children felt that being able to talk to the Leaders helped them to feel better about things that had worried them. There is a distinct feeling conveyed in their responses that the children recognised that the Club Leaders identified with them and this helped the children become engaged with sharing worries and issues within the group:

C22: It's like you...um... were worried about something you could...um tell one of the Leaders and they would discuss it in the group and you weren't so worried about it. (Transcript 2, lines 48-50)

C20: The Club Leaders say we should share our problems and they helped us and they knew how we feel .... and we can share everything with them (Transcript 2, lines 130-131 and 133)

The children also recognised the opportunity the Clubs provided to make more friends and be an active part of a group:

C8: You make friends (Transcript 1, line 29)

C18: Because it got us working as a team (Transcript 2, lines 35-38) 


\subsection{Changes and Benefits Noticed by Others}

The third theme identified changes and benefits that the children reported had been noticed in them by others, usually their parents. Question 6 of the focus group script specifically related to whether significant others had remarked upon changes they had noticed in them post-Pyramid Club:

C26: um my Mum said that I am talking...chatty (Transcript 3, line 76)

Children also reported talking at home to their parents about how much they liked coming to Pyramid:

C4: I had so much fun I told my Mum everything about Pyramid (Transcript 1, line 173)

The majority of children seemed eager to share with their families how much they had enjoyed the Pyramid Club and importantly no costs to attendees (e.g., perceived stigma see Stallard et al, 2007) could be identified by either children or their families in the narrative of any of the three transcripts.

\subsection{Changes Suggested by Children that Might Improve Pyramid}

The final theme encompassed children's suggestions for developing the Pyramid Club format. This gave the children the opportunity to express their views about any elements of the programme that they either particularly valued and wanted more of or conversely did not enjoy and would like to see changed. Many children suggested increasing the length of time spent at Pyramid either by extending the individual sessions or the number of weeks Pyramid Clubs ran:

\section{C25: I would like to change um that we get more time in Pyramid (Transcript 3, line 99)}

C22: I think more because it would make us feel even more confident (coughs) as much as others (Transcript 2, line 97)

C10: So it can stay open for 24 hours! (Transcript 1, line, 129)

Linked into requests for more time, were regrets about being unable to return the following school year:

C25: I don't want to leave because it was such fun, I am going to miss you and all the Pyramid Leaders and I wish there was more but I feel we have to give other children the chance (Transcript 3, lines 125-127)

C20: I wish you would come back and do it again (Transcript 2, line 153)

Some children were concerned about practical matters such as the location, number and type of activities, food and number of volunteer Club Leaders:

C27: Um if I think um...we had a little bit more space, and then we could play other games (Transcript 3, line 106)

C24: I wish there was less books around here (this Club was held in the school library) (Transcript 3, line 112)

C20: More teachers?

C17: ... and a man. (Transcript 2, lines 108 and 110)

C14: Having the food um maybe a little more earlier (Transcript 2, lines 80 and 82)

These suggestions provide valuable information as to what children enjoy and how the initiative can be made more appealing. However, an important indicator of the children's satisfaction was the high level of Club attendance, which was above $70 \%$ for each child.

\section{Discussion}

This study demonstrates the salience of Circle Time and therefore its potential suitability as a technique to elicit the views of child service users. In addition, it provides new insight into the quality and efficacy of the Pyramid intervention (Cooper, 2000; Davies, 1999; McKenna et al., 2013; Ohl et al., 2008; Ohl et al., 2012; Skinner, 1996) based on the views of the children rather than those of adults. Thematic analysis of the three Circle Time groups identified four overarching themes from the data each relating to a different perspective of measuring how the children had experienced attending Pyramid Clubs. The findings and implications of each theme are discussed as follows:

\subsection{How the Pyramid Club Experience Meets the Pyramid Intervention Ethos}

The Pyramid model draws upon Maslow's hierarchy of basic needs (Maslow, 1970) to identify what needs to be provided for children to be able to function and strive towards realisation of their potential (Ohl et al., 2012, Ohl et al., 2008; Pyramid, 2007). Overall, children reported valuing the 'nurturing' activities such as cooking, sharing food, and playing games. Furthermore, they mentioned a need to be praised for meeting goals and targets and a 
need for boundaries particularly the Club rules they themselves had created which made them feel safe. These findings concur with those reported in a review of the UK Child and Adolescent Mental Health Service (DCSF, 2008). The value of new experiences was also mentioned, the children clearly identifying that Pyramid Clubs gave them the opportunity to expand their horizons. However this extended beyond new activities and trips to include experiencing the responsibilities of being a member of a peer group that worked coherently together as a team and within which they felt accepted and valued (Harris, 1995).

\subsection{Self-Reported Changes and Benefits Attributed to Attending a Pyramid Club}

The second theme identified how Pyramid attendees reported changes and benefits to themselves that they attributed to having attended a Pyramid Club. Children consistently reported being less scared, less shy, less nervous and more confident. This concurs with improvements previously shown in post-intervention Strengths and Difficulties Questionnaires (SDQ, Goodman, 1999) Total Difficulty scores and changes in SDQ sub-scale scores (Ohl et al., 2012, Ohl et al., 2008), and provides important confirmation that the changes that teacher-raters have observed in the Pyramid attendees post-intervention corresponds with the experience of the children themselves and how they feel they have personally benefited from attending.

The children also reported benefits from their relationships with the volunteer Club Leaders. The children found the Club Leaders to be approachable and easy to talk to and the children appeared to value their advice. This gave the children the confidence to seek help when they needed and to share issues within the group and Circle Time. These valuable skills were likely to be lacking before and their acquisition is expected to lead to increased classroom participation which has been recognised as challenging for many quiet and socially withdrawn children (Ladd, Herald-Brown \& Raiser, 2008).

\subsection{Beneficial Changes Observed by Others}

Some children reported that friends and family (particularly parents) had reported changes in them after attending Pyramid. Most of the observed changes were related to increased verbal interaction and improved confidence levels with some parents observing improvements in practical academic areas e.g., handwriting. Children seemed keen to discuss Pyramid club with their parents and this discussion was overwhelmingly positive.

\subsection{Potential Costs of Attending Pyramid}

In a previous focus group study, children who volunteered in a playground inclusion scheme reported some personal costs involved in participating (Fox et al., 2006) which indicates that young children are willing to disclose negative experiences in such group evaluations.

Therefore it was considered important to investigate whether there might be personal costs for Pyramid attendees. One issue might be that as the intervention is selective then other children, not selected, might stigmatize those that are. Avoidance of this particular issue has been highlighted as an advantage of running universal school-based interventions (Stallard et al., 2007). However, there were no reports from the children of experiencing personal costs in the current study.

\subsection{How Pyramid Clubs Might be Developed}

The final theme addressed how the children felt Pyramid could be developed. The children were pragmatic and articulate in expressing their views. Many of the children wanted more time at the intervention. Others were more concerned with the facilities such as the location, wanting more space and having earlier refreshments as they were hungry at the end of the school day. These suggestions provide confirmation of what is valued by children in the Pyramid intervention and is evidence that children were able to use Circle Time to put forward their views with confidence.

Overall, this study highlights the importance of ensuring the voices of children as service users are heard. All the suggestions made by Pyramid attendees indicate the importance of ensuring that service user satisfaction evaluations incorporate measures and methods that are salient to the children in their role by identifying what their needs and expectations are and acting upon them (Day et al., 2006; Hennessy, 1999). Furthermore, in support of prior research (Ohl et al., 2012, Ohl et al., 2008) this study suggests that Pyramid offers socio-emotionally vulnerable children an opportunity to practice social skills and gain confidence facilitated by supportive and approachable adults in a familiar school-based setting.

\subsection{Limitations}

There are limitations to this study that need to be taken into consideration. Firstly, the study was based on three Pyramid Clubs only and, therefore, may be suggested to be unrepresentative of Pyramid Clubs as a whole. 
Although the number of Clubs is relatively low, Pyramid is a manualised intervention and, therefore, Clubs are delivered in a consistent manner with limited opportunities for Clubs to vary. The consistency of findings between the three Clubs indicates implementation fidelity of the intervention and also that there was a sufficient number of Clubs for the diversity of children's views to be identified and for saturation of the data to occur.

A second limitation may be argued to be that only one method of gathering children's views was used. Although triangulation of methods implies a more robust methodology, we did not wish to risk 'consultation fatigue' for ethical reasons (Worrall-Davies, 2008). However, these findings are consistent with data gathered from Pyramid Club children using other methods (McKenna et al., 2013, Ohl et al, 2012, Ohl et al., 2008) and this suggests that the study elicited a comprehensive account of the children's views. Future research could examine the efficacy of Circle Time in relation to other techniques for eliciting information directly from the child stakeholders, for example one to one interviews with an adult. However prior research (Sim, 1998) has suggested that children tend to be more relaxed when amongst their peers.

Thirdly, the lack of negative comments may suggest a lack of diversity of opinion and that children were giving socially desirable responses. However, it is our view that the children's suggestions for improvements are couched in a positive framework (e.g., 'we'd like to do more outside games') rather than a negative framework (e.g., 'the games were boring') as a result of the positive framing (DCSF 2008) of the Circle Time questions. In this way, the children were supported to make constructive proposals that can be fed back to service providers and inform further intervention development. Future research should compare the impact of positive versus negative question framing in this type of evaluation.

Finally, a potential methodological limitation of the study is that it is centred on children aged 8-9 years. This limitation is self-imposed by the age of the children taking part in the Pyramid clubs. However, given the number of children who take part in Pyramid Clubs nationally in the UK (around 3000 each academic year), these findings have wide applicability within Pyramid and to other UK School-based and Child and Adolescent Mental Health services delivered to this age group. It should be noted that Circle Time was a regular part of the Pyramid Club in which the children were taking part and, therefore, that the children were familiar with it as a technique. Therefore, future research needs to address whether this method can be used successfully with older or younger children in other interventions. An initial study by the authors (Fox et al., 2006) suggests that this may be the case and this is worthy of a more robust exploration.

From the current research it can be construed that the Circle Time technique appears to be an age-appropriate method for eliciting views from child service users aged 8-9 years. Where used as an existing technique within an intervention, Circle Time may be a cost-effective method of gathering children's views without the need for researcher input at the data gathering stage. However it is likely to be important that neutral facilitators, as used in the current study, run the Circle Time groups to avoid any response bias that could jeopardise the validity and diversity of the data. In addition, the participation of existing staff may increase the likelihood that children's views will be acted upon by service providers as knowledge of the rationale for action remains firmly within the service rather than being the main concern of researchers or consultants. However, a corollary of this is that existing staff may require training on the importance of service evaluation as a quality enhancement process in order to minimise possible 'evaluation anxiety' (Dalton, Elias \& Wandersman, 2001).

\subsection{Conclusion}

The aims of this study were twofold; firstly, to determine the views of the children who had participated in the Pyramid intervention and secondly, to investigate the use of Circle Time as a technique to elicit those views. Overall, the children evaluated their experiences of the Pyramid intervention positively and the reported benefits reflected closely the intended aims and ethos of the project. More importantly, self-reported improvements in terms of emotional well-being from the attendees provided confirmation of similar improvements shown in the results of prior evaluations of the Pyramid intervention (McKenna et al., 2013, Ohl et al., 2012; Ohl et al., 2008). In summary, the emergent themes from this study provide further evidence of the suitability and efficacy of the Pyramid intervention for supporting primary (elementary) school children in building social-emotional competencies. Importantly, these findings further validate the inclusion of children in the evaluation process of school-based emotional health and well-being interventions and are evidence that Circle Time is an appropriate and salient technique for eliciting the views of young children.

\section{References}

Alderson, P. (2010). Younger children's individual participation in 'all matters affecting the child'. In P. Percy-Smith, \& N. Thomas (Eds.), A handbook of young people's participation: Perspectives from theory and practice (pp. 88-96). London: Routledge. 
Boyatzis, R. E. (1998). Transforming qualitative information: Thematic analysis and code development. Thousand Oaks, CA: Sage.

Braun, V., \& Clarke, V. (2006). Using thematic analysis in psychology. Qualitative Research in Psychology, 3, 77-101. http://dx.doi.org/10.1191/1478088706qp063oa

Bryman, A. (2012). Social research methods (5th ed.). Oxford: Oxford University Press.

Cohen, J. (1960). A coefficient of agreement for nominal scales. Educational and Psychosocial Measurement, 20, 37-46. http://dx.doi.org/10.1177/001316446002000104

Cooper, C. (2000). A small-scale evaluation of the long-term outcomes for primary school children attending National Pyramid Trust therapeutic play clubs. University of East London. (Unpublished Manuscript).

Dalton, J., Elias, M., \& Wandersman, A. (2001). Community psychology: Linking individuals and communities. London: Thomson Learing.

Day, C. (2008). Children's and young people's involvement and participation in mental health care. Child and Adolescent Mental Health, 13, 2-8. http://dx.doi.org/10.1111/j.1475-3588.2007.00462.x

Day, C., Carey, M., \& Surgenor, T. (2006). Children's key concerns: Piloting a qualitative approach to understanding their experience of mental health care. Clinical Child Psychology and Psychiatry, 1, 139-155. http://dx.doi.org/10.1177/1359104506056322

Department for Children, Schools and Families. (DCSF). (2008). Improving the mental health and psychological well-being of children and young people: National child and adolescent mental health service review. London: DCSF.

Department for Education. (2013). National curriculum assessments at stage 2 in England, 2012-2013. SFR 34/2013. London: Department for Education.

Department of Health. (2004). National service framework for children, young people and maternity services. London: Department of Health.

DiBartolo, P. M., \& Grills, A. E. (2006). Who is best at predicting children's anxiety in response to a social evaluation task? A comparison of child, parent and teacher reports. Journal of Anxiety Disorders, 20, 630-645. http://dx.doi.org/10.1016/j.janxdis.2005.06.003

Field, A. P., Lawson, J., \& Banerjee, R. (2008). The verbal threat information pathway to fear in children: The longitudinal effects on fear cognitions and the immediate effects on avoidance behaviour. Journal of Abnormal Psychology, 117, 214-224. http://dx.doi.org/10.1037/0021-843X.117.1.214_

Fox, P., Ohl, M., Hughes, B., Haye, D., Mitchell, K., \& Graham, B. (2006). A focus group study of children taking part in emotional well-being initiatives in London. Report prepared for The King's Fund by Pyramid and University of West London, London.

Goodman, R. (1999). The Strengths and Difficulties Questionnaire: A research note. Journal of Child Psychology and Psychiatry, 38, 581-586. http://dx.doi.org/10.1111/j.1469-7610.1997.tb01545.x

Graham, A., \& Fitzgerald, R. (2011). Supporting children's social and emotional well-being: Does 'Having a Say'matter? Children \& Society, 25, 447-457. http://dx.doi.org/10.1111/j.1099-0860.2010.00295.x

Harris, J. R. (1995). Where is the child's environment? A group socialisation theory of development. Psychological Review, 102, 458-489. http://dx.doi.org/10.1037/0033-295X.102.3.458

Hennessy, E. (1999). Children as service evaluators. Child Psychology and Psychiatry Review, 4, 153-161. http://dx.doi.org/10.1111/1475-3588.00270

Hrushka, D. J., Schwartz, D., Cobb-St John, D., Picone-Decaro, E, Jenkins, R. A., \& Carey J. W. (2004). Reliability in coding open-ended data: Lessons learned from HIV behavioural research. Field Method, 16, 307-331. http://dx.doi.org/10.1177/1525822X04266540

Ladd, G. W., Herald-Brown, S. L., \& Reiser, M. (2008). Does chronic classroom peer rejection predict the development of children's classroom participation during the Grade School years? Child Development, 79,1001-1015. http://dx.doi.org/10.1111/j.1467-8624.2008.01172.x

Landis, J. R., \& Koch, G. (1977). The measurement of observer agreement for categorical data. Biometrics, 33, 671-679. http://dx.doi.org/10.2307/2529310

Maslow, A. H. (1970). Motivation and personality. New York, NY: Harper \& Row. 
McKenna, A. E., Cassidy, T., \& Giles, M. (2013). Prospective evaluation of the Pyramid Plus psychosocial intervention for shy withdrawn children: An assessment of efficacy in 7- to 8-year-old school children in Northern Ireland. Child and Adolescent Mental Health. http://dx.doi.org/10.1111/camh.12023

Mihalic, S. F., Irwin, K., Elliott, D., Fagan, A., \& Hansen, D. (2001). Blueprints for violence prevention. Washington DC: U.S. Department of Justice.

Mrazek, P. J., \& Brown, C. H. (2002). An evidence-based literature review regarding outcomes in psychosocial prevention and early intervention in young children: Final report. In C. Russell (Ed.), The state of knowledge of prevention/early intervention. Canada: Invest in Kids.

Ohl, M., Mitchell, K., Cassidy, T., \& Fox, P. (2008). The Pyramid club primary school-based intervention: Evaluating the impact on children's social-emotional health. Child and Adolescent Mental Health, 13, 115-221. http://dx.doi.org/10.1111/j.1475-3588.2007.00476.x

Ohl, M., Fox, P., \& Mitchell, K. M. (2012). Strengthening socio-emotional competencies in a school setting: Data from the Pyramid project. British Journal of Educational Psychology, 83, 452-466. http://dx.doi.org/10.1111/j.2044-8279.2012.02074.x

Sim, J. (1998). Collecting and analysing qualitative data: Issues raised by the focus group. Journal of Advanced Nursing, 28, 345-352. http://dx.doi.org/10.1046/j.1365-2648.1998.00692.x

Stallard, P. (1995). Parental satisfaction with intervention: Differences between respondents and non-respondents to postal questionnaire. British Journal of Clinical Psychology, 34, 397-405. http://dx.doi.org/10.1111/j.2044-8260.1995.tb01474.x

Stallard, P. (2001). Reducing parental dissatisfaction with a child and adolescent psychology service: A process of quality improvement. Journal of Mental Health, 10, 63-73. http://dx.doi.org/10.1080/09638230123673

Stallard, P., Simpson, N., Anderson, S., Hibbert, S., \& Osborn, C. (2007). The FRIENDS emotional health programme: Initial findings from a school-based project. Child and Adolescent Mental Health, 12, 32-37. http://dx.doi.org/10.1111/j.1475-3588.2006.00421.x

Strauss, A., \& Rbin, J. (1998). Basics of qualitative research: Grounded theory procedures and techniques. London: Sage.

Worrall-Davies, A. (2008). Barriers and facilitators to children's and young people's views affecting CAMHS planning and delivery. Child and Adolescent Mental Health, 13, 16-18. http://dx.doi.org/10.1111/j.1475-3588.2007.00456.x

Worrall-Davies, A., \& Marino-Francis, F. (2008). Eliciting children's and young people's views of child and adolescent mental health services: A systematic review of best practice. Child and Adolescent Mental Health, 13, 9-15. http://dx.doi.org/10.1111/j.1475-3588.2007.00448.x

\section{Copyrights}

Copyright for this article is retained by the author(s), with first publication rights granted to the journal.

This is an open-access article distributed under the terms and conditions of the Creative Commons Attribution license (http://creativecommons.org/licenses/by/3.0/). 